\title{
O BEETHOVEN-SCHRIFT: RICHARD WAGNER TEÓRICO
}

Henry BURNETT ${ }^{1}$

- RESUMO: Quando consideramos a extensão da obra dramática de Richard Wagner, não causa estranheza que seus textos teóricos sejam praticamente desconhecidos. No entanto, um de seus escritos, intitulado Beethoven, influenciou decisivamente a elaboração de um livro famoso, hoje considerado um capítulo importante da história da estética, O nascimento da tragédia. Este artigo pretende analisar este escrito de Wagner na intenção de desvendar o que pode ter sido tão determinante na leitura que Nietzsche fez dele, e que o levou ao ponto de citá-lo de modo efusivo no primeiro prefácio da sua obra de estréia, dedicado àquele que, até então, era seu grande mestre e amigo e, como veremos, uma influência não só musical, mas também teórica.

- PALAVRAS-CHAVE: Richard Wagner; Friedrich Nietzsche; Beethoven-Schrift; música alemã.

Quando Nietzsche redige o primeiro prefácio para $O$ nascimento da tragédia, no final de 1871, dedicado a Richard Wagner, afirma que o livro foi escrito com base na leitura de um texto do compositor, o Beethoven. Uma leitura detida desse texto pode ser útil para quem se dedica ao estudo do livro de estréia de Nietzsche. Para além de seu caráter festivo - o texto foi dedicado ao compositor homônimo -, o Beethoven revela com muita clareza as idéias estéticas de seu autor, com indicações precisas sobre um ponto muito importante para Nietzsche: a influência de Schopenhauer sobre a concepção da Obra de arte total. Eis o que diz o prefácio:

1 Professor de Filosofia da Universidade Federal de São Paulo (Unifesp). Artigo recebido em 01/2009 e aprovado em 03/2009. 
Haverás de lembrar com isso que eu colecionava esses pensamentos ao mesmo tempo em que surgira teu esplêndido escrito em homenagem a Beethoven, quer dizer, em meio ao susto e grandiosidade da guerra que acabara de irromper. (Nietzsche, 1999, p. 23)

Héctor Julio Pérez López destaca a importância e as implicações do Beethoven.

[...] o aspecto mais conhecido da recepção wagneriana de Schopenhauer é o valor da filosofia pessimista como refúgio para o artista, consequência de ter sofrido o desencanto de seu período revolucionário; o Beethoven-Schirft não trata explicitamente do pessimismo, mas sim de apresentar outra face da recepção da filosofia de Schopenhauer: a da filosofia da música. (López, 2001, p. 116)

Para Wagner, como se sabe, a leitura de O mundo como vontade e representação foi de grande importância. Essa ligação é nítida desde as primeiras linhas de seu texto. "Admite-se que a linguagem dos sons pertence, de modo uniforme, a toda a humanidade e que a melodia é a língua absoluta por meio da qual o músico fala aos corações" (Wagner, 1983, p. 39). ${ }^{2}$ Wagner retoma a hierarquização das artes proposta por Schopenhauer, acreditando que nem a língua nem qualquer traço nacional do compositor permitem identificá-lo com o pintor ou com o poeta que criam limitados pela linguagem e pelas imagens pátrias. O que existe como criação absoluta, i.e., para além do caráter nacional e linguístico, é a melodia, que Wagner chama de "língua absoluta" (absolute Sprache). Nietzsche vai repetir Wagner quando falar da melodia em $O$ nascimento da tragédia; ela também será tratada como um fundamento musical anterior à linguagem, um elemento universal, "espelho musical do mundo". Wagner declara livremente que o lugar que a música ocupa em sua obra é uma herança. "Pois foi Schopenhauer o primeiro que reconheceu e designou, com uma claridade filosófica, a posição da música em relação às outras belas artes e lhe atribuiu uma natureza diferente às da arte pictórica e poética" (Wagner, 1983, p. 43).

Essa distinção da pintura e da poesia parece menos depreciativa em Schopenhauer, que distingue as artes com base em uma hierarquia aparentemente natural, enquanto Wagner acredita que um Schiller e um Goethe são mais facilmente capturáveis, porque deixaram "informações conscientes" (bewußten Mitteilungen) sobre si mesmos, o que não aconteceu no caso de Beethoven, que permanecia insondável.

2 No Brasil existe uma tradução do Beethoven, feita por Theodomiro Tostes. As citações remetem à edição alemã, com base na qual fiz algumas modificações na tradução brasileira. As demais citações de Wagner, salvo indicação contrária, são traduções livres. 
Se, para o poeta, a linguagem seria o ponto referencial, para o pintor, de forma análoga, o ambiente serviria como motivo; entretanto, o objeto do músico nunca é nítido. Encontrando a essência de sua linguagem e de sua expressão, Wagner acreditava atingir a essência da própria música. Com o que ambos concordam é que a diferença entre os exercícios artísticos reside na intuição da idéia - tomada em Wagner também em seu sentido platônico -, é ela que pode diferenciar as artes. O inconsciente é a única fonte para chegar-se à essência do fazer musical, pois o músico é o único que cria com base na intuição. O músico cria com base em uma ausência de consciência, enquanto o poeta e o pintor criam, necessariamente, amparados por ela. Analisar a obra de Beethoven exigiria, portanto, essa solução filosófica.

Podemos apontar algumas ligações imediatas nessa apropriação de Schopenhauer por Wagner. De início, interessa a Wagner o caráter objetivo das coisas, sua aparência, opostos da coisa-em-si e da essência. Ele quer encontrar o lugar de nascimento da intuição musical.

Se considerarmos, neste ponto, a condição que Schopenhauer estabelece para a entrada da idéia na nossa consciência, isto é, 'uma predominância temporária do intelecto sobre a Vontade, ou, do ponto de vista fisiológico, uma forte excitação da atividade intuitiva do cérebro sem nenhuma excitação das inclinações e das emoções', só nos resta examinarmos rigorosamente a explicação segundo a qual a nossa consciência tem duas faces: em parte, ela é consciência do nosso próprio eu, isto é, da Vontade; em parte, ela é consciência de outras coisas e, como tal, conhecimento intuitivo do mundo exterior ou apreensão dos objetos. (Wagner, 1983, p. 45)

Como o próprio Schopenhauer fez, Wagner utiliza o exemplo do sonho para mostrar como se dá essa dupla via da consciência. No sonho, vemos aquilo que nos é vedado no estado de vigília; no caso da música, ela chega a seu criador como uma manifestação exterior ao que seria um mundo em vigília, ou melhor, ao que seria um mundo de imagens; o compositor é possuído pela idéia original. O duplo sonho/vigília é substituído pelo duplo som/imagem.

Consequentemente, nós podemos dizer que ao lado do mundo do som há um mundo da luz, e que eles reagem em relação um ao outro como o sonho em relação à vigília [...]. Do mesmo modo que o plástico mundo do sonho, sensível pela intuição, não pode tomar forma senão por uma atividade especial do cérebro, assim a música só penetra em nossa consciência por uma atividade cerebral semelhante. (Wagner, 1983, p. 46)

O sonho é a analogia mais próxima da forma de manifestação da essência da música, pois, por meio dele, se é capaz de atingir o mundo das idéias eternas. Se, para Schopenhauer, a criação musical não poderia ser atingida senão por essa aproximação análoga ao sonho - na verdade, o processo que 
se vivencia em sonho só se repete na vigília na forma de "sentimentos obscuros" (dunkle Gefühle) -, Wagner não hesita em atribuir à música a condição de exterioridade em relação às categorias de espaço e tempo, já que está ligada a outro nível de experiência: "Vem daí o fato de Schopenhauer concluir, de maneira tão convincente, pela formação de sonhos fatídicos premonitórios, que tornam perceptíveis as coisas mais diferenciadas, e até mesmo por casos raros e extremos de clarividência sonambúlica" (Wagner, 1983, p. 47).

A música age como uma antevisão de lugares e forças (estéticas) nunca atingidas, pois é gerada por um ato de negação da Vontade, que por sua vez aponta sempre para os desejos conscientes. Vem dessa inclinação a conclusão de Wagner, que julga a manifestação musical ter tudo a ver com um tipo de experiência onírica, por ser também de natureza supra-sensível. Seria o modo mais verossímil de aproximação com a natureza, enquanto possibilidade de participar da essência das coisas. Pode-se concluir que a "criação" (Schaffen) e a "contemplação" (Anschauung) artísticas só nascem quando a consciência afasta-se das excitações da Vontade.

Apesar de julgar as artes plásticas capazes de promover essa aproximação, já que seu conteúdo é a aparência ilusória do mundo revelada por meio da luz, Wagner cita Goethe para mostrar que a pintura não tem o poder de revelar o primordial.

A consciência, que através de si mesma nos permitiu, na visão da aparência, atingir a idéia que nela se manifesta, poderia finalmente ser obrigada a exclamar como Fausto: 'Que espetáculo! Mas - ai de mim! - só um espetáculo! Por onde te apanharei, natureza infinita? (Wagner, 1983, p. 49)

O "recurso" serve aqui para apontar o objetivo nuclear do ensaio: a exaltação desenfreada da música. "Quem responde a este chamado com total segurança é a música" (Wagner, 1983, p. 49). Assim, as artes plásticas são culpadas de ter objetivado a apreciação pura e simples das obras de arte, que só elevam nossa alma mediante uma identidade entre seu conteúdo e nossa Vontade, que não fala a nossa voz primordial. Esse é o equívoco mais comum quando se compara a experiência visual e a musical. O conceito de beleza não poderia estar ligado apenas com a contemplação, pois nela está contida a aparência, como objeto, e a intuição, como sujeito. O que está em plano de fundo para Wagner é a negação de qualquer mediação do conceito na criação e na apreciação da música, que se expressa como uma "exteriorização imediata dos afetos da vontade" (Wagner, 1983, p. 49), i.e., como um produto da natureza. A esse respeito, vale transcrever a passagem em que Wagner vincula a Vontade, a natureza e a música. "[...] esta idéia é compreendida por nós como uma revelação direta dessa unidade da 
vontade, que se apresenta à nossa consciência a partir da unidade do ser humano em união com a natureza e sentida, da mesma forma, imperiosamente, através do som" (Wagner, 1983, p. 50).

Apesar desse vínculo estreito, a recepção de Schopenhauer por Wagner não é isenta de discordâncias. O confronto da música com a poesia, à luz de Schopenhauer, permite-nos observar que havia laços que os aproximavam com muita estreiteza, mas que também os distanciavam - Wagner, Schopenhauer, mas também Nietzsche. Essa identidade teórica está longe de ser um ponto pacífico nos comentários:

Enquanto Schopenhauer defendia com intransigência a natureza heterogênea, prioritária e autônoma da música com respeito à palavra, Wagner afirmava exatamente o inverso, a superioridade da palavra significante, a única capaz de dar uma determinação ao sentimento expresso musicalmente: a música é estéril sem a palavra. (Tagliabue, 1993, p. 35)

Essa distinção entre a música e a palavra parece ser um dos pontos inconciliáveis entre a estética de Wagner e a de Schopenhauer, mas a recepção dessa questão ainda rendeu momentos intensos, vide o texto clássico (publicado nos anos 1930) de Denis de Rougemont, que nos soa infantil quase um século depois.

A lembrança da influência de Schopenhauer sobre Wagner é um segundo lugar comum da crítica - aliás, absolutamente contraditório àquele que atribuía a Tristão a glorificação do desejo sensual. Embora Nietzsche e o próprio Wagner possam pensar o contrário, essa influência, a meu ver, é bastante superestimada. Um criador da estatura de Wagner não põe 'idéias' na música. Que ele tenha em Schopenhauer algumas fórmulas utilizadas no libreto, uma coerência intelectual que justificasse a seus próprios olhos algumas de suas opções, eis, sem dúvida, o que devemos reter dessa influência, o que, aliás, não tem maior interesse. A ascese, a negação do mundo criado, a identificação da atração sexual com o querer-viver que oblitera o conhecimento, toda essa mística, logo tachada de budista, nada tinha a ensinar a Wagner [...]. Que Wagner restituiu o sentido perdido da lenda na sua virulência integral não é uma tese a demonstrar, é a própria evidência declarada na música e nas palavras da ópera. Através da ópera, o mito atinge sua perfeição. (Rougemont, 1988, pp. 164-5)

Apesar da parcialidade, o desfecho de seu argumento é pertinente, o compositor foi, de fato, responsável por grande parte da renovação do mito no século XIX, mas também é verdadeiro que toda utilização da genialidade de Wagner como justificativa para seu isolamento teórico, tomando os termos do comentário, é, no mínimo, insuficiente. Não é possível justificar uma independência de Wagner em relação a Schopenhauer simplesmente porque o próprio Wagner deu testemunho dessa influência de forma nítida, como, de resto, podemos ler no Beethoven. Para Wagner, o ato de criação do músico é 
o elo que permitirá atingir o essencial da música, tal ato deve ser diferenciado de todos os outros, em qualquer que seja o domínio artístico. Desde o início, a posição de Wagner sobre a figura do músico está nitidamente desenvolvida sob o modelo schopenhaueriano de superioridade da música. ${ }^{3}$

Existe uma carta de Wagner a Frédéric Villot - "Louvre-Konservator" que pode ser útil neste momento. A carta foi intitulada como Música do futuro. A um amigo francês como prefácio à tradução em prosa de meus versos operísticos (Zukunftsmusik. An einen französischen Freund als Vorwort zu einer Prosa-Übersetzung meiner Operndichtungen); nela, entre outras coisas, Wagner faz um esboço da história e do desenvolvimento da ópera, sintetiza suas principais teses e elabora uma autocrítica formal de sua produção teórica. Aqui encontramos outro retrato nítido da filiação teórica de Wagner à estética schopenhaueriana.

Se, quanto à literatura, a diversidade das línguas européias é um obstáculo a esta qualidade [de universalidade], na música, [que é] uma língua igualmente inteligível a todos os homens, deveria existir a grande potência conciliadora, a qual, ao diluir a linguagem dos conceitos na das emoções, transmitisse a todos o mais secreto da concepção do artista, sobretudo quando a transmissão através da expressão plástica da representação dramática lhe desse aquela claridade que só a pintura, até hoje, pôde reclamar como seu exclusivo privilégio. (Wagner, 1982, pp. 186-7) ${ }^{4}$

Isso tudo mostra que existia um ambiente no qual as discussões em torno da música e da filosofia se desenvolviam. Mas, para além de detalhes temporais - o momento em que Nietzsche leu os textos de Wagner, e viceversa, ou o momento em que os dois leram Schopenhauer -, é preciso assegurar que não há uma identidade se construindo, embora existam inegáveis afinidades e mesmo temas comuns: a poesia, a música, a filosofia, os gregos. Uma pequena mostra desses entrecruzamentos pode ser percebida já a partir da primeira das conferências de Basiléia, em que Nietzsche irá expor os motivos da dissolução do drama musical antigo; Wagner, na carta supracitada (que data de setembro de 1860), comentando o texto Ópera e drama, conta.

3 Adorno também menciona a posição metafísica da música na ótica de Schopenhauer: "Daí a transcendência [da música] em face da engrenagem cotidiana da autoconservação, transcendência que levara Schopenhauer a colocá-la no topo da hierarquia das artes, como objetivação imediata da vontade" (Adorno, 1983, p. 262).

4 Informações sobre essa carta em Dellin, 1983, p. 93. Outro comentário afirma que essa carta foi escrita por Wagner para tentar corrigir erros e mal-entendidos sobre suas teorias, e que fora destinada principalmente ao público francês, como um movimento de resposta à retaliação sofrida por parte de Berlioz, que ironizou a qualidade da partitura de Tristão e Isolda. Ironicamente, o comentador afirma que a mensagem não foi entendida, pois foi redigida em alemão (Schneider, 1991, pp. 28-9). 
Pus-me então a investigar o que caracteriza essa dissolução tão deplorada da grande arte grega, e este estudo me ocupou por longo tempo. Chamou logo minha atenção um fato singular: a separação, o isolamento dos diferentes ramos da arte, reunidos antigamente no drama completo. (Wagner, 1982, p. 192)

Nietzsche vai apropriar-se do tema, apesar de tomar um rumo distinto ao final. Além de Schopenhauer, Wagner e Nietzsche também tinham em comum o gosto pelo crítico e escritor alemão Gotthold Ephraim Lessing. Wagner, ainda seguindo a carta supracitada, afirma.

Confirmando a autoridade de um dos mais importantes críticos de arte, por exemplo, tendo em mãos as investigações de um Lessing sobre os limites da pintura e da poesia, acreditei possuir um resultado sólido, a saber: que cada arte tende a ser uma extensão indefinida de sua potência, e que esta tendência a conduz finalmente a seu limite e que não poderia franquear este limite sem correr o perigo de perder-se no incompreensível, no extravagante e no absurdo. (Wagner, 1982, p. 192)

Wagner parece aglutinar a autoridade de Lessing da mesma forma como antes havia feito com Schopenhauer, o que demonstra uma sutil dependência teórica. Veremos no que toca a Lessing que Nietzsche será muito mais crítico que Wagner, demonstrando que havia uma moralidade viciada em seus textos, apesar de seu belo e peculiar estilo, que Nietzsche nunca cansou de elogiar. Já Wagner não critica, não interfere no texto de Lessing - como, de resto, também não parece ter como entrar em franca oposição com Schopenhauer -, apenas acredita estar em consonância com o crítico, e isso é suficiente. Apesar do grande fôlego, Wagner busca, até no jovem filólogo Nietzsche, um respaldo teórico em que se possa se ancorar.

Voltemos ao Beethoven. Wagner vai considerar o papel do músico de um ponto de vista absurdamente parcial, i.e., com base em si mesmo. Ao lhe atribuir uma suposta superioridade, acaba por fazê-lo com base em um ocultamento e apequenamento dos processos de criação da poesia e das demais artes.

Um objeto tal a que o músico, através de uma pura contemplação, deve dar o caráter de ideia, não se apresenta absolutamente a ele. Sua música já é por si mesma uma ideia do mundo, representação imediata da sua essência, ao passo que, nas outras artes, ela só se tornará representada e transmitida através do conhecimento. (Wagner, 1983, p. 50)

Aparentemente funcionando como um elogio a Beethoven, Wagner parece falar de si próprio. Essa tarefa tão grandiosa que ele arvorava para si não era uma simples intenção, era o que acredita ser seu destino, isso é quase um consenso nos livros a seu respeito: que ele criou um mito em torno de si, proposital e conscientemente. Mas essa autoafirmação quer o tem- 
po todo o amparo de Schopenhauer, pois no músico desperta a Vontade universal, enquanto no artista plástico apenas a vontade individual, i.e., o músico comunica o primordial, o que está antes e além de tudo, a "idéia consciente do mundo" (bewußte Idee der Welt); ninguém pode estar acima dessa experiência, só os santos, em sua natureza imperturbável e imutável. ${ }^{5}$ Essa aproximação, curiosamente, não é mencionada por Nietzsche nos textos do período, o que demonstra sua parcimônia temporária; no entanto, para ilustrar isso, basta lembrarmos o diagnóstico dessa degenerescência fatal do ascetismo de Wagner na III dissertação da Genealogia da moral.

Para mostrar que essa experiência de transcendência e revelação foi vivida por ele mesmo, Wagner relembra duas histórias em que esse estado onírico de elevação teria sido presenciado. Ele descreve o dia em que o canto de dois gondoleiros venezianos - numa noite em que a insônia o perturbava - conduziu-o a um estado de semitorpor, quando os sons ecoavam num grande canal, e o fez reconhecer uma velha melodia com versos de Tasso. "Que poderia dizer-me de dia uma Veneza iluminada pela luz do sol, que este sonoro sonho noturno não pudesse trazer à minha consciência de um modo mais infinitamente profundo e espontâneo?" (Wagner, 1983, p. 52).

Adiante, recorda o canto de um pastor; em sua descrição, a voz ressoava e reverberava nas montanhas, o que o levava a pensar que os dois picos rochosos estivessem conduzindo o próprio vale a sair do silêncio, dialogando com aquele homem. Em ambos os casos, Wagner quer mostrar que sua consciência interior transformara cenas paradisíacas em elos com, talvez, o ser das coisas, o som primordial, tendo seu gênio como instrumento.

Ele [o músico], como que em estado de um leve sonho, é tocado através do ouvido, mais do que pela ilusão visual, assim o seu ser íntimo se integra na essência daquilo que ele percebe, e é também apenas nesta percepção que se revela verdadeiramente a essência das coisas que lhe são exteriores. (Wagner, 1983, p. 53)

Wagner afirma que o arrebatamento da música é capaz de gerar o esquecimento da sensibilidade visual, pois a intensidade do olhar altera-se; e explica de modo curioso o resultado que uma audição musical pode gerar nos ouvintes.

Nós experimentamos isto em qualquer sala de concertos ao escutar uma peça musical que verdadeiramente nos comove, enquanto se desenrola diante de nós um espetáculo que, por si mesmo, poderia distrair-nos da música e dar-nos até vontade de rir. Refiro-me ao aspecto do auditório e à impressão de vulgaridade que ele produz, bem como aos gestos dos executantes, acessório, aliás, indispensável a uma produção orquestral. (Wagner, 1983, p. 53)

5 "Porque sua arte [a do músico], em relação com o conjunto de todas as outras artes, é, na verdade, como a religião para a igreja" (Wagner, 1983, p. 51). 
É impossível não pensar no cenário do próprio drama wagneriano, em que a música é, em muitos momentos, posta de lado, em função do enredo envolvente que lhe é peculiar, com seus mitos, deuses e reis. Wagner não menciona a importância do teatro, por exemplo, dentro de uma montagem dramática. Seu elogio a Beethoven tem uma face dupla: mostrar a grandeza da música do autor na Nona sinfonia e, ao mesmo tempo, fazer ver sua própria condição de gênio.

Mas o que é a essência da música, que Wagner julga ter encontrado? A capacidade de revelar, por meio da rítmica - sem a qual a música não seria perceptível -, as imagens que, naquele complexo modo de apreensão, são vistas com olhos de nosso interior, enquanto nas artes plásticas são reveladas por meio da "contemplação refletida" (reflektierenden Anschauung), i.e., o filtro do conhecimento, do conceito.

Com isso, a música, ao atrair para o seu domínio, que é também o domínio do sonho, os elementos do mundo fenomenal mais ligado a ela, faz com que o conhecimento intuitivo se volte para o interior, por meio da transformação milagrosa que nela se produz; ali, ela tem então a faculdade de apreender a essência das coisas em sua manifestação mais imediata e de interpretar a imagem que o músico, no seu sono profundo, teve o privilégio de contemplar. (Wagner, 1983, p. 55)

Wagner, ao aproximar-se do desfecho da primeira parte do texto, encerra esse trecho reiterando uma adesão quase reverente a Schopenhauer. "Sobre as relações da música com as formas plásticas do mundo fenomenal, assim como dos conceitos abstraídos das próprias coisas, é impossível que seja produzido algo mais iluminado do que tudo o que, a esse respeito, já foi dito na obra de Schopenhauer [...]" (Wagner, 1983, p. 55).

Mas é aqui, sob esse manto de aceitação, que Wagner ousa um passo adiante. Acreditando que o vínculo entre a música e as artes plásticas fazse por uma impossibilidade de compreensão do verdadeiro sentido da primeira, na medida em que se aplicam à música as mesmas condições de apreciação das artes plásticas, Wagner vê na essência musical um elemento que não existe na apreciação plástica: o "sublime" (Erhabenen).

Desde que se apodera de nós, ela [a música] excita o êxtase supremo que vem da consciência do ilimitado. Isto, em contrapartida, só se realiza em nós, como consequência da relação com as artes plásticas, após uma longa e profunda contemplação da obra artística, isto é, depois de nos livrarmos (temporariamente) da ação da vontade individual. (Wagner, 1983, p. 56)

É aqui, portanto, que Wagner se afasta de Schopenhauer, ao negar a supremacia da Vontade sobre nossa consciência. A música gera em nós a integração com o que é essencial, ou talvez mais do que isso, a música supre- 
ma faz ver dentro de nós o fundamento de todas as coisas, tornando-se uma fonte inesgotável de criação divina. Como se não fosse suficiente essa dimensão sublime da música, o texto é ainda uma declaração clara do ascetismo wagneriano, como se vê na citação de Palestrina, em que os elementos musicais não são suficientes para lhe apreciar devidamente nem a sucessão harmônica dos acordes, nem a rítmica, mas sim algo de outro domínio. "[...] é uma revelação inteiramente espiritual que nos enche de uma comoção indescritível, pois nos traz à consciência a mais pura essência religiosa, livre de todo fictício conceito dogmático" (Wagner, 1983, p. 57).

Por fim, Wagner volta a mencionar a superioridade da experiência musical sobre os elementos plásticos da cena; trata-se de uma indicação clara de seu rompimento com a forma clássica da ópera - sabe-se que tanto o bel canto italiano como os balés franceses e a ópera romântica formavam o essencial daquela tradição da qual Wagner quis sempre estar à frente. Encerrando a primeira parte do texto, bem mais teórica que a segunda, em que ele vai falar explicitamente de Beethoven em relação com Bach, Mozart e Haydn, Wagner faz uma crítica ao papel secundário que a música assume nas exibições de dança, sinfonias orquestrais e óperas. Para ele, essas exibições são do domínio do "mundano" (weltlich), enquanto Palestrina e sua elevação espiritual estariam no campo do "espiritual" (geistlichen).

O mais curioso é que Wagner julga estar de fato rompendo com essa tradição, i.e., que seu drama musical significa a afirmação da música sobre as demais formas de expressão, fazendo crer que sua obra está contra os espetáculos que desviam nossa atenção da essência dos sons. Ao que tudo indica, sua revolução deveria ser um retorno a Beethoven, ainda que ele o quisesse ultrapassar, mas sua música deveria ser tão grandiosa quanto a de seu precursor. Sem dúvida, Beethoven é um dos mestres de Wagner, como afirma Schneider: "O que deve ser entendido por 'música'? Evidentemente a música pura, a sinfonia. É aqui que entra em cena, após um longo eclipse, o primeiro mestre de Wagner: Beethoven" (Schneider, 1991, p. 54). Mas uma questão se apresenta: Wagner não seguirá ou não terá o talento de seu mestre Beethoven para as sinfonias, como afirmará Nietzsche? Questão intrincada quando se pensa no valor de sua obra, e do quanto, por exemplo, as vanguardas do início do século XX são dele herdeiras: Schönberg, por exemplo. ${ }^{6}$ Basta, por enquanto, que pensemos no papel que ele se atribui no Beethoven, a saber: seguir os passos do mestre faz parte do cumprimento da grande tarefa a que se propôs. "É sobre este caminho, valendo-se desta profunda e íntima experiência, que o espírito alemão deve guiar o seu povo, assim ele está destinado, ele deve fazer a felicidade dos outros povos" (Wagner, 1983, p. 109).

6 Wagner influenciaria toda uma geração posterior, que, a seu modo, também rompeu com ele. Ver, por exemplo, Meyer, 2000. 
O texto fecha-se sobre si mesmo, com a exaltação da Alemanha de Beethoven e, consequentemente, com a certeza de que ele mesmo detém o cetro que vai conduzir o espírito alemão. Mas insisto em que, em muitos momentos, é como se ele estivesse escrevendo contra si mesmo, negando sua influencia da tradição operística européia, indicando que seu drama seria a revolução alemã mais radical da história; só que, a música que virá por suas mãos não cabe na descrição crítica que ele elabora, antes o vincula a ela.

A música, ao abandonar assim seu estado de sublime inocência, perde a força de nos redimir da culpa, pois, em vez de trazer-nos a revelação das essências das coisas, junta-se à aparência ilusória das coisas exteriores a nós. Como esta espécie de música exige também ver alguma coisa a mais, este explícito elemento torna-se o fator principal, como demonstra claramente a 'ópera'; o espetáculo, o balé etc., atrativos e interessantes, destacam-se e superam, às vezes, como atração, o próprio acompanhamento musical. (Wagner, 1983, pp. 59-60)

Nietzsche lerá essas páginas com muita atenção e paixão, elas serão definitivas para a elaboração de seus textos estéticos, ainda que as ligações políticas venham a ser um dos pontos mais tensos do conflito com Wagner. Essa importância da música como caminho de livramento terá um peso decisivo no jovem Nietzsche, ele vai acreditar nessa capacidade infinita de libertação.

Tagliabue tem uma hipótese muito pertinente sobre essa relação inicial, que está no entorno da leitura do Beethoven feita por Nietzsche:

O conflito foi o choque de dois protagonistas [e, continua], mesmo não se prescindindo do caráter pessoal impresso por Nietzsche em sua polêmica, que é um dado de fato, é possível considerá-la sob dois aspectos: um mais fútil, para não dizer piedoso, do qual poderemos em breve nos desembaraçar, e um mais sério. (Tagliabue, 1993, p. 6)

Ao mesmo tempo em que existem dois projetos culturais, temos também uma abordagem, por parte de Nietzsche, ora profundamente cômica, quando o assunto são suas divergências com Wagner, ora séria, quando resolve tratar teoricamente de suas diferenças. No que toca à tríade - em que também Schopenhauer é protagonista -, Tagliabue diz o seguinte:

No nosso caso, o duplo aspecto desse tipo de gesto resulta manifesto quando nos damos conta de que o conflito ao qual Nietzsche dava o caráter biográfico de caso pessoal com o amigo Wagner era, na realidade, em boa parte, um distanciamento ideológico do pensamento de Schopenhauer. (Tagliabue, 1993, pp. 7-8)

Há muito a ser dito quando o assunto são as relações entre os três autores, mas um ponto tem uma importância central, que é, sempre que Nietzsche critica Wagner, ele está criticando Schopenhauer: "Wagner não era 
assim tão schopenhaueriano como ele se representava. Mas Nietzsche não queria combater um pensamento, mas sim uma mentalidade, um costume, um lugar de valor" (Tagliabue, 1993, p.53), quer dizer, Wagner reflete Schopenhauer, por isso a crítica de Nietzsche a este último encerra-se muito cedo, logo sendo revertida com toda a intensidade contra Wagner, que, em seu teatro, cumpria, para Nietzsche, o princípio moral de Schopenhauer; Nietzsche não combateria um filósofo solitário sem antes combater um artista público. Os principais pontos de divergência - "[...] a denúncia pessimista da existência, o amor intenso como compaixão [...], o convite ao remorso e à renúncia, a adesão ao ascetismo cristão: todas essas noções que, com efeito, se encontram mais em Schopenhauer que em Wagner" - são, portanto, ecos de uma impressão multifacetada de seus dois antecessores: "ambos [Schopenhauer e Wagner], diz Nietzsche, me são mestres tão profundamente aparentados quanto antagonistas, eu sou o primeiro de ambos a destilar uma espécie de unidade" (Tagliabue, 1993, p. 51). ${ }^{7}$ Pensando apenas em Wagner, podemos vê-lo, ao lado de Nietzsche, confrontado com uma Grécia mitificada, buscando na música perdida do povo heleno uma sombra de seus desejos de revolução cultural no seio da Alemanha.

Wagner, em seu Beethoven, está quase sempre manipulando conceitos de Schopenhauer, mas isso não significa que ele tenha sido um seguidor fiel ou quiçá um bom intérprete; como afirmou Tagliabue no trecho supracitado, Wagner não é tão schopenhaueriano quanto talvez desejasse ser, embora se aproprie de sua terminologia: "[...] no artista plástico, a pura contemplação faz calar a vontade individual, no músico desperta a vontade universal" (Wagner, 1983, p. 50). O que disso tudo nos interessa é que, apesar das divergências no que toca à leitura que Wagner fez de Schopenhauer, é preciso não superestimar a autonomia de Nietzsche em relação ao Beethoven; pode-se dizer que os escritos que lhe são contemporâneos O nascimento da tragédia e os escritos preparatórios - têm com ele uma forte identificação, como diz Giuliano Campioni:

O projeto nietzschiano desta fase está completamente ligado ao Wagner do Beethoven [...]. Todo o projeto de $O$ nascimento da tragédia aponta na direção de um renascimento de uma cultura orgânica (de acentuado caráter hierárquico) sobre a base estética afinada com a potência do encanto onírico visionário suscitado do gênio musical, segundo a tese do Beethoven de Wagner [...]. O dionisíaco de Nietzsche contém, no centro, o tema da autonomia mágica da música do Beethoven. (Campioni, 1993, p. 203-4)

7 A carta citada por Tagliabue foi endereçada a Georg Brandes, de Nizza, em 19 de fevereiro de 1888: "[...] jener mir ebenso tief verwandten als antagonistischen Meister. (-ich war der Erste, der aus Beiden eine Art Einheit destillirte" (Nietzsche, 2003, p. 260). 
Nietzsche vai reafirmar a importância do Beethoven na seção 16 do livro de estréia, ao tratar da música como uma arte cuja origem é diversa de todas as demais, numa crítica nítida à estética da bela forma.

Sobre esse reconhecimento, que é o mais importante de toda a estética, e só com o qual ela começa num sentido realmente sério, Richard Wagner imprimiu seu selo, para corroborar sua eterna verdade, quando em seu 'Beethoven' estabelece que a música deve ser medida segundo princípios estéticos completamente diferentes dos de todas as artes figurativas e, desde logo, não segundo a categoria da beleza: ainda que uma estética errada, pela mão de uma arte extraviada e degenerada, tenha se habituado a exigir da música, a partir daquele conceito de beleza vigente no mundo figurado, um efeito parecido ao das obras de arte figurativa, a saber, a excitação do agrado pelas belas formas. Após tomar conhecimento dessa enorme antítese, senti uma forte necessidade de me aproximar da essência da tragédia grega e com isso da mais profunda revelação do gênio helênico [...]. (Nietzsche, 1999, p. 104) ${ }^{8}$

Mas sabemos que a ruptura teórica com Wagner é, com razão, bastante obscurecida por elementos biográficos, e que isso tem um papel importante, como mostra a carta abaixo, em que ele fala do quase trágico rompimento.

[...] e nada pode compensar para mim o fato de ter perdido, no último ano, a simpatia de Wagner. Eu sonho frequentemente com ele, e sempre no estilo de nossos encontros íntimos de então. E nós nunca falamos uma palavra hostil entre nós, nem nos meus sonhos, só palavras encorajadoras e joviais, com ninguém talvez eu tenha rido tanto. Agora acabou - e o que adianta ter razão em vários assuntos que eu possa ter contra ele! Como se isso pudesse apagar a simpatia da memória! Eu já vivi muitas coisas semelhantes, e parece que vivo novamente agora. São os sacrifícios mais duros que o caminho de minha vida e de meu pensamento exigiram de mim. (Carta a Peter Gast, Marienbad, 20 de agosto de 1880 [Nietzsche, 2003, p. 36])

Tal posicionamento crítico foi decisivo na obra de Nietzsche, por mais duro que tenha sido o afastamento. No entanto, nos textos que orbitam em torno de $O$ nascimento da tragédia pode-se assegurar que a onipotência do músico está na sua imediata identificação com a Vontade única originária, tal e qual a concepção wagneriana, que, por sua vez, tem amparo enviesado em Schopenhauer. A saída desse labirinto não é fácil de ser encontrada.

BURNETT, Henry. The Beethoven-Schrift: theoretical Richard Wagner. Trans/ Form/Ação. São Paulo, v.32(1), 2009, p.159-173.

8 Tradução ligeiramente modificada a partir da versão de Jacó Guinsburg, 1993, p. 97-8. 
- ABSTRACT: If we consider the magnitude of the Richard Wagner's dramatic work, it will be not strange to realize that his theoretical texts are almost entirely unknown. However, one of his writings, entitled Beethoven, exercised decisive influence upon the composition of The birth of tragedy, a famous book regarded nowadays as an essential moment of the history of aesthetics. The purpose of this paper is to examine this Wagner's writing aiming to unriddle which determinative motive brought Nietzsche to mention it enthusiastically in the original foreword of his first work, dedicated to whom which, until that moment, were his master and friend and exercised upon him an influence both musical and theoretical.

- KEYWORDS: Richard Wagner; Friedrich Nietzsche; Beethoven-Schrift; German music.

\section{Referências bibliográficas}

ADORNO, T. W. "Ideen zur Musiksoziologie". Musikalische Schriften I. Gesammelte Schriften. Frankfurt am Main: Surhkamp, 1978. Tradução brasileira de Roberto Schwartz. São Paulo: Abril Cultural, Col. Os Pensadores, 1983).

CAMPIONI, Giuliano. "Wagner 'histrio'". Sulla Strada di Nietzsche. Pisa: Ets, 1993.

DELLIN, Martin Gregor-. Wagner-Chronik. Munique/Kassel/Basileia/Londres: DTV/ Bärenreiter, 1983.

Richard Wagner. Sein Leben, Sein Werk, Sein Jahrhundert. Munique/Zurique: Piper, 2001.

HAAR, Michel. "La rupture iniciale avec Schopenhauer". Nietzsche et la métaphysique. Paris: Gallimard, 1993.

"La critique nietzschéenne de Schopenhauer". Par-delá le nihilisme. Paris: Presses Universitaires de France, 1998.

LÓPEZ, Héctor Julio Pérez. "A la búsqueda del genuino origen arcaico de la tragedia. La filología amiga del wagnerismo nietzscheano". Il Saggiatore Musicale, Anno VII, nº 1, Florença, Leo S. Olschki, 2000.

Hacia el nascimento de la tragedia: un ensayo sobre la metafísica del artista en el joven Nietzsche. Milão: Res Publica, 2001.

MEYER, Christian (ed.). "Schönberg und Wagner. 3. Wagner Tage in Graz: Bericht zum Symposium, 3. Oktober 1998". Viena: Arnold Schönberg Center, 2000.

NIETZSCHE, Friedrich. Kritische Studienausgabe. Ed. de Giorgio Colli e Mazzino Montinari. Munique: DTV/Walter de Gruyter, 1999, nova edição.

. Sämtliche Briefe. Kritische Studienausgabe. Munique/Berlim/Nova York: DTV/de Gruyter, 2003, $2^{\mathrm{a}}$ tiragem.

Friedrich Nietzsches Briefe. Historisch-Kritische Gesamtausgabe Ed. de Karl Schlechta und Wilhelm Hoppe. Munique: C. H. Beck'sche Verlagsbuchlandung, 1938-1942.

Obras incompletas. Trad. de Rubens Rodrigues Torres Filho. São Paulo: Abril Cultural, 1974. 
NIETZSCHE, Friedrich. O nascimento da tragédia. Trad. de Jacó Guinsburg. São Paulo: Companhia das Letras, 1993.

ROUGEMONT, Denis de. O amor e o Ocidente. Trad. de Paulo Brandi \& Ethel Brandi Cachapuz. Rio de Janeiro: Guanabara, 1988.

SCHNEIDER, Marcel. Wagner. São Paulo: Martins Fontes, 1991.

TAGLIABUE, Guido Morpurgo. Nietzsche contro Wagner. Pordedone: Studio Tesi, 1993.

WAGNER, Richard. "Zukunftsmusik". Briefe an einen französischen Freund (als Vorwort zu einer Prosa-Übersetzung seiner Operndichtungen). Ausgewählte Schriften. Ed. de Esther Drusche. Leipzig: Philipp Reclam, 1982.

. Beethoven. Dichtungen und Schriften, vol. IX. Ed. de Dieter Borchmeyer. Frankfurt am Main: Insel, 1983.

- Beethoven. Trad. de Theodomiro Tostes. Porto Alegre: L\&PM, 1987.

. "Libretos". Col. Universal-Bibliothek. Stuttgart: Reclam, 1953. 